CUADERNOS DE ESTUDIOS GALLEGOS, LXVI Núm. 132 (enero-diciembre 2019), págs. 107-136

ISSN: $0210-847 \mathrm{X}$

https://doi.org/10.3989/ceg.2019.132.04

\title{
LA RECUPERACIÓN DE UN PRIVILEGIO PERDIDO DE ALFONSO IX AL HOSPITAL DE PEREGRINOS DE SANTA MARÍA DE O CEBREIRO (1186) A PARTIR DE UNA COPIA DEL SIGLO XIX*
}

\author{
Francisco Saulo Rodríguez LaJusticia \\ Universidad de Cantabria \\ ORCID iD: https://orcid.org/0000-0002-9194-8360
}

* Quiero expresar mi agradecimiento a Rosa Lamas Casado, bibliotecaria del Museo Etnolóxico de Ribadavia (Ourense), por haberme facilitado la consulta de algunos trabajos publicados en Galicia, inaccesibles para mí desde la distancia.

Copyright: (C) 2019 CSIC. La edición electrónica de esta revista se distribuye bajo los términos de una licencia de uso y distribución Creative Commons Reconocimiento 4.0 Internacional (CC BY 4.0).

Cómo citar/Citation: Francisco Saulo RodRÍGUez LaJUSTICIA, "La recuperación de un privilegio perdido de Alfonso IX al hospital de peregrinos de Santa María de O Cebreiro (1186) a partir de una copia del siglo XIX", Cuadernos de Estudios Gallegos, 66, núm. 132 (2019), págs. 107-138, https://doi.org/10.3989/ceg.2019.132.04 


\title{
LA RECUPERACIÓN DE UN PRIVILEGIO PERDIDO DE ALFONSO IX AL HOSPITAL DE PEREGRINOS DE SANTA MARÍA DE O CEBREIRO (1186) A PARTIR DE UNA COPIA DEL SIGLO XIX
}

\begin{abstract}
RESUMEN
El objetivo de este artículo es dar a conocer una confirmación de privilegios que Alfonso IX, rey de León, concedió al hospital de peregrinos de Santa María de O Cebreiro en 1186. Considerado un documento perdido y, por lo tanto, estando ausente en la colección diplomática que de este monarca publicó Julio González en 1944, presenta la peculiaridad de haber sido realizada mientras Alfonso todavía era un infante durante el reinado de su padre, Fernando II, lo que permite incidir en el estudio de las actuaciones de los hijos durante el reinado de sus padres.

Palabras Clave: Alfonso IX, privilegio, propiedades, hospital, Cebreiro, 1186.

\section{A RECUPERACIÓN DUN PRIVILEXIO PERDIDO DE AFONSO IX AO HOSPITAL DE PEREGRINOS DE SANTA MARÍA DO CEBREIRO (1186) A PARTIR DUNHA COPIA DO SÉCULO XIX}

\section{Resumo}

O obxectivo deste artigo é dar a coñecer unha confirmación de privilexios que Afonso IX, rei de León, concedeu ao hospital de peregrinos de Santa María de O Cebreiro en 1186. Considerado un documento perdido e, por tanto, estando ausente na colección diplomática que deste monarca publicou Julio González en 1944, presenta a peculiaridade de ser realizada mentres Afonso aínda era un infante durante o reinado do seu pai, Fernando II, o que permite incidir no estudo das actuacións dos fillos durante o reinado dos seus pais.

Palabras Clave: Afonso IX, privilexio, propiedades, hospital, Cebreiro, 1186.

\section{THE RECOVERY OF A LOST PRIVILEGE AWARDED BY ALFONSO IX TO THE PILGRIMS HOSPITAL OF SANTA MARÍA DE O CEBREIRO (1186) BY MEANS OF A $19^{\mathrm{TH}}$ CENTURY COPY.}

\begin{abstract}
The objective of this article is to present a confirmation of a privilege that Alfonso IX, king of León, granted to the hospital of pilgrims of Santa María de O Cebreiro in 1186. Considered a lost document and, therefore, absent from the diplomatic collection that Julio González published in 1944 about this king, it has the peculiarity of having been made while Alfonso was still an infant during the reign of his father, Fernando II, so this document is also a good instrument to study a son's behavior during his father's reign.
\end{abstract}

KeY words: Alfonso IX, privilege, properties, hospital, Cebreiro, 1186. 
Recibido/Received: 29/11/2017

Aceptado/Accepted: 28/05/2018

\section{IDENTIFICACIÓN DE LA FUENTE*}

No cabe ninguna duda del inmenso valor de las copias para conocer el contenido de documentos cuyos originales se han perdido. Adoptando las debidas precauciones en tanto en cuanto una copia puede contener a veces importantes alteraciones con respecto al original, bien por descuidos bien como consecuencia de la voluntad de adulterar ${ }^{1}$, lo cierto es que los historiadores no pueden permitirse el lujo de reconstruir el pasado únicamente a partir de la documentación original puesto que, entonces, la información recopilada sería infinitamente menor y los datos quedarían muy inconexos ${ }^{2}$.

Esta función de complementar a originales perdidos, faceta valorada por cualquier estudioso que haya realizado colecciones documentales ${ }^{3}$, cobra, a mi juicio, una especial importancia cuando los historiadores ya habían dado por desaparecidos los documentos y éstos "reaparecen" en lugares insospechados,

\footnotetext{
* Siglas empleadas: coord., coords.= coordinador(es); ibíd.= ibídem; pág., págs.= página (s); v.= véase; vol., vols. $=$ volumen $(\mathrm{es})$.

1 Para una perspectiva general muy acertada sobre este tema en época medieval, v. CoMISIÓN INTERNACIONAl de Diplomática, Falsos y falsificaciones de documentos diplomáticos en la Edad Media, Zaragoza, Real Sociedad Económica Aragonesa de Amigos del País, 1991.

2 El caso de Alfonso IX resulta una clara muestra de lo que afirmo si tenemos en cuenta que, como señalaba Manuel Lucas, sólo se habrían conservado un $34^{\prime} 6 \%$ de documentos originales frente a un $65^{\prime} 4 \%$ que se trata de copias: Manuel LuCAs Álvarez, El reino de León en la Alta Edad Media. Vol. V: Las cancillerías reales (1109-1230), León, Centro de Estudios y de Investigación "San Isidoro", Caja España de Inversiones, Caja de Ahorros y Monte de Piedad y Archivo Histórico Diocesano, 1993, pág. 504 (Fuentes y estudios de historia leonesa, núm. 53).

3 Citando un caso suelto de los centenares a los que podría aludirse, es lo que afirmaba Maurilio Pérez cuando, al hablar del tumbo de la catedral de León, incidía en que en él se hallan copiados muchísimos documentos que de otro modo no se conservarían: Maurilio Pérez González, "Originales y copias en la documentación latina medieval", Minerva. Revista de filología clásica, 3 (1989), pág. 241.En la misma línea, Manuel Romero considera que si hay muchísimos ejemplares resulta más viable que algunos o aunque sea uno se salve, si pocos, lo normal es que desaparezcan todos. La copiosidad de ejemplos o copias de libros y documentos, completos o en extracto, es una medida secular que se ha demostrado eficaz en su poder de conservación frente a los más variados avatares: v. Manuel RomERo TALLAFIGO, De libros, archivos y bibliotecas. Venturas y desventuras de la escritura, Gobierno de Canarias, Las Palmas de Gran Canaria, 2008, pág. 48.
} 
aunque no sea tal y como fueron expedidos en su momento. El caso del diploma que presento en este artículo podría enclavarse dentro de esta casuística.

Atribuido por error a Alfonso X y datado sin explicación aparente en 1262, se conservan en la Real Academia Galega (A Coruña) dos hojas de papel sellado de 1813 que contienen la copia de una confirmación de privilegios realizada en beneficio del hospital de peregrinos de Santa María de O Cebreiro ${ }^{4}$. Según la información que proporciona la plataforma digital Galiciana, este documento forma parte de los que pertenecieron a Manuel Murguía, marido de Rosalía de Castro y personaje bien conocido en Galicia, incorporándose a los fondos de la Real Academia Galega en 1964 gracias a la donación que la hija menor de éste, Gala Murguía, hizo de los papeles de su padre ${ }^{5}$.

Cuando se examina el texto y se entiende su estructura, al momento se observa que Alfonso X no tuvo nada que ver con este documento y lo que realmente sucedió fue que quien realizó la primera copia del mismo, en 1760, cometió el error de atribuírselo, perpetuándose así el fallo y llegando incluso hasta nuestros días, como puede verse en la ficha descriptiva de Galiciana.

Puede indicarse como atenuante que las confusiones entre unos reyes y otros son, por desgracia, mucho más frecuentes de lo que sería deseable $\mathrm{y}$, en este sentido, Alfonso X el Sabio ha sido identificado en más de una ocasión como Alfonso IX ${ }^{6}$, atendiendo, como advertía Jesús Lalinde, a la diferencia de numeración que el rey ofrece respecto a León y Castilla ${ }^{7}$.

Examinando con cierto detenimiento las dos hojas de papel que se encuentran en la Real Academia Galega lo que encontramos en su interior, descartado el protagonismo de Alfonso X en este asunto, es una confirmación de privilegios en latín concedida por su abuelo paterno, Alfonso IX de León, en el año 1186 (sub

\footnotetext{
4 Arquivo de la Real Academia Galega, Depósito 1, caixa 547, 17.

5 Xunta de Galicia, Galiciana. Arquivo dixital de Galicia [en línea], disponible en <http://arquivo. galiciana.gal/arpadweb/gl/inicio/presentacion.cmd $>$ [Consulta: 30/09/2017]. La descripción literal de este documento es Privilexio de Alfonso X ao Hospital de Santa María do Cebreiro.

6 Por ejemplo, Gregorio López, Ignacio SAnPonts y Barba, Ramón Martí de EiXala y José Ferrer Y Subirana, Las Siete Partidas del sabio rey don Alfonso el IX, Barcelona, Imprenta de Antonio Bergnes, 1843-1844.

7 Jesús Lalinde Abadía, "Reflexiones ante la semblanza de Alfonso X de León y IX de Castilla", $M e$ dievalia, 10 (1992), pág. 237. Las confusiones entre unos reyes y otros son especialmente abundantes en la Corona de Aragón por el hecho de que determinados monarcas, los llamados Pedro o Alfonso, presentan un número menos en Cataluña y dos menos en Valencia, de manera que, por ejemplo, Pedro III el Grande (1276-1285) es conocido por los catalanes como Pedro II o Pere el Gran y por los valencianos como Pedro I. No deja de ser algo estrambótico cuando uno lee a algunos historiadores pasajes del estilo Para la coronación romana de Pedro I: Damian Smith, «Motivo y significado de la coronación de Pedro

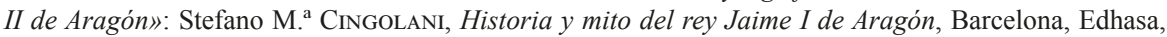
2008, pág. 443. Un caso especialmente llamativo de confusión es también Carlos Marichalar, Colección diplomática del rey don Sancho VIII (El Fuerte) de Navarra, Pamplona, Aramburu, 1934, que se refiere en realidad a Sancho VII (1194-1234).
} 
era $M C C X X I I I I)$ o, lo que es lo mismo, en un momento en el que todavía reinaba el padre de éste, Fernando II.

Puede resultar extraño de entrada que Alfonso IX aparezca intitulado como rey cuando todavía vivía su padre y cuando éste ejercía como tal. Lo que en otras circunstancias o con otros personajes podría entenderse como una usurpación del trono o incluso como una mentira deliberada del documento se descarta desde el momento en que comprobamos cómo Fernando II asoció al trono al infante Alfonso al poco de su nacimiento y que, como afirmaba Inés Calderón, así aparecerá durante todo el reinado, primero junto a su madre, después junto a la segunda esposa de su padre y, finalmente, junto a su última madrastra, doña Urraca López ${ }^{8}$.

Efectivamente, ya desde el momento de su nacimiento, el infante Alfonso aparece mencionado en los documentos con el título de rey, siendo el primero de ellos de entre los que hacen relación a Galicia la devolución del señorío de Tui que Fernando II, una cum coniuge mea regina domna Urraca et filio meo rege Adefonso, hizo en abril de 1170 a favor del obispo Juan?

A partir de este momento, la acción conjunta del padre y el hijo (unas veces con la reina y otras sin ella, por lo menos en lo que a su mención se refiere) es prácticamente una constante, llegando, según Julio González, hasta el 13 de septiembre de 1187 , fecha del último documento en que ambos aparecen citados juntos en la confirmación que la familia real hizo de Castrotierra y de las villas de Santa Cristina, Gallegos, Matanza y Cañizar a favor de la iglesia de León ${ }^{10}$.

Atendiendo a esto, no resulta nada extraño por consiguiente la plena actuación de Alfonso mientras todavía vivía su padre y que, además, utilizara el título de rey. Identificado pues el protagonista correcto, es el momento de estudiar el documento en relación con el hospital lucense de peregrinos de Santa María de O Cebreiro.

\footnotetext{
8 Inés CALderón Medina, Cum magnatibus regni mei. La nobleza y la monarquía leonesas durante los reinados de Fernando II y Alfonso IX (1157-1230), Madrid, Consejo Superior de Investigaciones Científicas, 2011, pág. 443.

9 Manuel Recuero Astray, Paz Romero Portilla y M. a Ángeles Rodríguez Prieto, Documentos medievales del reino de Galicia: Fernando II (1155-1188), s. 1., Xunta de Galicia, 2000, págs. 139-142. Se trata de los documentos 113 y 114 de la colección que, en realidad, no son más que dos copias de un mismo diploma. Este documento, si su data es correcta, obligaría a adelantar en por lo menos un año la fecha tradicional del nacimiento de Alfonso IX, fijada por Julio González en 1171 a partir de los datos obtenidos del Cronicón Conimbricense que, no obstante, él mismo enjuicia por presentar algunos detalles dudosos que le llevan a sospechar de la fecha exacta: Julio GonzÁlez GonzÁLEZ, Alfonso IX, Madrid, Instituto "Jerónimo Zurita”, 1944, vol. I, pág. 23.

10 Julio González González, Regesta de Fernando II, Madrid, Instituto “Jerónimo Zurita”, 1943, pág. 514.
} 


\section{LA monarquía leonesa y el hospital de Santa María de O Cebreiro EN EL SIGLO XII}

Volviendo a la gran obra de referencia cuando se habla de Alfonso IX, la colección documental realizada por Julio González, de nada sirve para estudiar la relación de este monarca con $\mathrm{O}$ Cebreiro puesto que los diplomas trabajados por el autor sólo son los que expidió como rey de pleno derecho tras la muerte de su padre, esto es, a partir de 1188.

En este sentido, el hospital de peregrinos tan sólo aparece mencionado en su trabajo una única vez cuando el 19 de octubre de ese mismo año

comparecieron ante la reina madre varios obispos, entre ellos don Pedro de Compostela, y los priores de Santa María de Villafranca $y$ de la Orden del Hospital de Cebrero para liquidar una desavenencia, que se resolvió por medio de arbitrales, ya que antes no se habian arreglado ${ }^{11}$.

Quien quizá mejor conoce la historia de O Cebreiro, después del ya fallecido párroco Elías Valiña ${ }^{12}$, es Luis López, autor de varios trabajos sobre la región y sobre la institución en concreto en los que explica con detalle el principal motivo de la pérdida de la documentación original: tres incendios acontecidos a mediados del siglo XV, en 1629 y en 1641 en los que no solamente se perdieron para siempre importantísimos documentos, también fueron reducidos a cenizas, libros, tallas, muebles y otros objetos de indudable valor ${ }^{13}$.

Ateniéndonos a la información que el autor ofrece sobre la relación del hospital de peregrinos con la monarquía leonesa del siglo XII, Luis López proporciona los siguientes datos:

Año 1156

Donación que hizo la reina doña Urraca, hija del rey don Alonso y de doña Constanza, al hospital del Cebreiro, de la villa de Perex (Pereje) y su coto...

\footnotetext{
11 Ibíd., vol. I, pág. 59.

12 Es numerosa la bibliografía existente sobre Elías Valiña Sampedro, escrita incluso mientras aún vivía: v. por ejemplo, Luis Celeiro Álvarez, Elías Valiña, Santiago de Compostela, Xunta de Galicia, 1996.

13 Luis López Poмвo, "Archivo del priorato de Nuestra Señora del Cebreiro (Lugo)", Estudios de genealogía, heráldica y nobiliaria de Galicia, 12 (2016), pág. 97. También es interesante Luis LóPez PomBo, O Cebreiro. Apuntamentos históricos e documentais, Lugo, Deputación de Lugo, 2013.
} 
1160, 6 de noviembre

Privilegio del rey don Fernando el Santo con su mujer doña Urraca, los cuales dan al hospital del Cebreiro el lugar de Zanfoga y Pereje...

1186. Era 1224.

Privilegio de don Alonso I, el cual viviendo su padre don Fernando el Santo, cota todas las heredades, casas, molinos y a Perex (Pereje) y a las casas y heredades, que tienen en Villafranca el coto de Santa María de Bercianos y el Río Curel...

\section{7, 4 de febrero}

Privilegio del Rey don Fernando con su hijo don Alonso, en que conceden y confirman al hospital del Cebreiro las donaciones y concesiones que su padre el emperador y su abuelo el rey don Alonso, concedieron a dicho hospital...

1231, 29 de diciembre. Era de 1269.

Amparo del Cebreiro y confirmación de sus cotos.

Privilegio del Rey don Fernando, que confirmó el del rey don Alonso su padre, el cual recibe al Hospital del Cebreiro, en su amparo, y a sus bienes, muebles y raices, y le confirma los cotos que el rey don Fernando, su padre, y los pasados, le concedieron...

\section{Era 1221.}

Privilegio del rey don Alonso el Sabio, el cual dio (...) propiedad al hospital del Cebreiro, que tenía en el monte de Connavia, en cuyo distrito existe el monasterio... ${ }^{14}$.

Las inexactitudes históricas que contiene este fragmento saltan a la vista, puesto que, a excepción de en la presunta confirmación de 1231, todos los monarcas que aquí se citan están incorrectamente identificados puesto que la reina Urraca había fallecido ya en 1126 y Fernando el Santo y Alonso el Sabio, esto es Fernando III y Alfonso X respectivamente, son reyes del siglo XIII que ni siquiera habían nacido en el momento en que Luis López les atribuye todos estos privilegios $^{15}$.

\footnotetext{
${ }^{14}$ López Pombo, “Archivo del priorato...”, págs. 99-100.

15 Imagino, no obstante, que el autor lo que hace es indicar literalmente lo que consta en la fuente de la que saca los datos (Describo y resumo aquí, los documentos que forman el legajo 3214 de la sección de
} 
Por otra parte, la pérdida de todos estos documentos a causa de los incendios impide por completo conocer de ellos más que lo que ya han dicho otros autores como fray Antonio de Yepes o Elías Valiña, quien básicamente toma los datos del primero y a quien Luis López sigue muy de cerca para esta época.

Las colecciones documentales de los reyes leoneses realizadas en distintos momentos del siglo pasado e incluso de éste no ayudan tampoco prácticamente nada porque ni siquiera contienen menciones a los mismos.

Empezando por la teórica donación de Urraca I es evidente que la donación no pudo efectuarse en 1156, porque esta reina ya había fallecido en 1126. Elías Valiña apunta la fecha de 1118 sugiriendo implícitamente con ello que el documento estaba datado en el año 1156 de la Era Hispánica, lo que encajaría con el reinado de Urraca ${ }^{16}$. Si existió este documento, lo cierto es que ni siquiera aparece su mención en ninguna de las dos colecciones documentales que se le han dedicado a la reina Urraca $^{17}$.

Los privilegios que, en teoría, corresponderían a Fernando II, esto es el de 1160 y el de 1187, no aparecen ni en la monografía de Julio González sobre este rey ni en la recopilación de diplomas relativos a Galicia que de este monarca elaboraron Manuel Recuero, Paz Romero y M $\mathrm{M}^{\mathrm{a}}$ Ángeles Rodríguez.

Las imprecisiones aumentan por la confusión de fechas que existe entre los diferentes historiadores. Así, por ejemplo, Juan Uría, basándose a su vez en las indicaciones proporcionadas por el padre Yepes, data en 1166 un tercer privilegio de Fernando II del que destaca las siguientes palabras:

\section{Concedo et confirmo hospitali montis Zebruarii donationes quas pater meus imperator, pro auusque meus Rex Adephonsus, ipsi}

\footnotetext{
clero del A.H.N.: ibíd., pág. 98) y que, en realidad, no se trata de fallos suyos, lo que no obsta, a mi juicio, para que se hubiera hecho la pertinente aclaración acerca de los errores de identificación de todos estos monarcas. En justicia debe decirse que cuando se habla de Fernando y de Alfonso, aunque no sean los del siglo XIII y por lo tanto no sean ni el Santo ni el Sabio, sí que se corresponden con los del siglo XII, esto es, con Fernando II y Alfonso IX siendo el primero el padre del segundo.

${ }^{16}$ Elías Valiña Sampedro, "El Cebrero en el camino de Santiago a través de Galicia", Compostellanum, 9, vol. 4 (1964), pág. 698.

${ }_{17}$ Cristina Monterde Albiac, Diplomatario de la reina Urraca de Castilla y León (1109-1126), Zaragoza, Anubar, 1996 e Irene RuIz AlBI, La reina Doña Urraca (1109-1126): cancillería y colección diplomática, León, Centro de Estudios e Investigación "San Isidoro", 2003. Sería plausible pensar que pudiera tratarse de Urraca, hija de Alfonso VII, que todavía vivía en 1156 y que había sido reina consorte de Pamplona hasta 1150 por su matrimonio con García Ramírez el Restaurador. Sin embargo, es evidente que tampoco puede tratarse de este personaje porque no era hija de Constanza de Borgoña -como señala la mención a la que alude Luis López- y porque en esta época se encontraba como gobernadora en Asturias sin un poder efectivo sobre Galicia.
} 


\section{praedicto hospitali et Fratribus ibidem sub Regula Beati Geraldi de gentibus, diuina inspiratione, in perpetuum, sunt largitae ${ }^{18}$.}

Este mismo documento, que Elías Valiña ubica también en $1166^{19}$, aparece datado en los trabajos de Luis López en 1186 sin que se especifique el motivo, mientras que Julio González lo consideraba como un diploma sin fechar sin que llegara a aclarar el motivo por el que lo clasificó de esta manera cuando otros autores sí que han proporcionado fechas, aunque sean dispares ${ }^{20}$.

Se equivoque quien se equivoque, la inexistencia del texto original impide por completo salir de dudas acerca de un diploma del que, como es fácil imaginar a tenor de lo visto, tampoco aparece en las recopilaciones de Julio González ni de Manuel Recuero, Paz Romero y M $\mathrm{M}^{\mathrm{a}}$ Ángeles Rodríguez.

En cuanto a los de Alfonso IX, uno de ellos sería éste de 1186 al que dedico este artículo y otro la donación que el monarca leonés hizo de los montes de Connavía. Sobre este último, también hay problemas de datación en tanto en cuanto el propio Luis López apunta dos fechas distintas en sus trabajos ${ }^{21}$, mientras que Elías Valiña apunta una tercera posibilidad al haberlo llevado al último año del reinado de Alfonso X, esto es, a $1284^{22}$.

Una vez más, parece claro que hablamos de documentos desaparecidos cuya fecha $-o$ incluso existencia-nunca podremos comprobar y que, por este motivo, no aparecen ni en los trabajos que Julio González dedicó a Fernando II y a Alfonso IX ni en el recopilatorio de regestas que Manuel González y M $\mathrm{M}^{\mathrm{a}}$ Antonia Carmona hicieron sobre la documentación de Alfonso $X^{23}$.

\section{LAS CIRCUNSTANCIAS DE ELABORACIÓN DEL DOCUMENTO}

Teniendo en cuenta la estructura interna del diploma cuyo estudio abordo, debemos hablar de tres momentos históricos diferentes a la hora de estudiarlo:

En primer lugar, la elaboración del original por parte de Alfonso IX en un año, 1186, en el que todavía reinaba su padre, Fernando II. Independientemente de

\footnotetext{
${ }^{18}$ Luis VÁzquez de Parga Iglesias, José M. a Lacarra de Miguel y Juan Uría Ríu, Las peregrinaciones a Santiago de Compostela, Madrid, Consejo Superior de Investigaciones Científicas, 1948-1949, vol. II, pág. 314. Identifico a Juan Uría como autor por ser él quien redactó el capítulo en el que se encuentra este fragmento.

19 Valiña Sampedro, "El Cebrero...”, pág. 698.

${ }^{20}$ González González, Regesta de..., pág. 516.

${ }^{21}$ En su monografía de 2013 se da el año 1189, lo que implicaría ya a un Alfonso IX reinando en solitario: López Pombo, Apuntamentos..., pág. 14. En su artículo de 2016 el año que aparece es 1184, lo que supondría que aun compartiría el poder con su padre: LóPEz PoмBO, “Archivo del priorato...”, pág. 100.

22 VAliña SAMPedro, "El Cebrero...", pág. 699.

23 Manuel González Jiménez y María Antonia Carmona RuIz, Documentación e itinerario de Alfonso X el Sabio, Sevilla, Secretariado de Publicaciones de la Universidad de Sevilla, 2012.
} 
que luego dedicaré un espacio específico a esta cuestión, parece claro que la confirmación de privilegios al hospital de peregrinos de O Cebreiro constituye una acción clara por parte de Alfonso de transmitir una imagen de política continuista con respecto a la de su padre.

El asunto tiene su importancia si se tiene en consideración la proximidad de la sucesión en el trono y las pretensiones de Urraca López de Haro, a quien su padre conocía desde comienzos de los años ochenta, con quien Fernando II acabaría contrayendo matrimonio en 1187 y quien pretendía que la corona real fuera a parar no a Alfonso, sino a su hijo Sancho.

Si bien la voluntad de Fernando II pareció no resquebrajarse nunca y tener claro desde su nacimiento que su primogénito heredaría el trono, es fácil pensar que la influencia de Urraca intranquilizara a un Alfonso que podía temer que su padre cambiara de opinión.

Ante una eventual necesidad de apoyos, Alfonso se presenta en la confirmación de privilegios de marzo de 1186 a favor del hospital de Santa María de O Cebreiro como alguien generoso y estrechamente ligado a su padre, con quien reina (Regnante rege Fernando cum filio suo rege / Alfonso Legione, Galecia, Asturiis et Extremisdorii) y a quien reconoce su primacía en la cláusula de corroboración del diploma: hoc scriptum quod aut[o]/ritate patris mei rege Fernandi fieri iussi propio (sic) rob[o]/re confirmo.

Por otra parte, esta política de confirmación de privilegios concedidos por monarcas anteriores tuvo su continuidad a partir de la muerte de Fernando II en 1188 hasta el punto de que, como afirmaba Manuel Lucas, el abundante número de documentos de Alfonso IX puede llevar a una visión exagerada de la actividad innovadora del monarca y de su cancillería en tanto en cuanto no conllevan nuevas concesiones, sino que son simples confirmaciones de donaciones o privilegios $^{24}$.

Es fundamental además para comprender el documento de marzo de 1186 en todas sus dimensiones tener muy presente, como recordaba Manuel Recuero, la protección que Alfonso IX brindó a algunos de los hospitales del Camino de Santiago, como el que había construido un canónigo de Astorga, cerca de la puerta del obispo; u otro en Arbas, al que otorgó un realengo para que pudiera hacer frente a su abastecimiento ${ }^{25}$, además de la predilección que el rey sentía

\footnotetext{
${ }^{24}$ LuCAs Álvarez, El reino de León..., pág. 491.

25 Manuel Recuero Astray, “Alfonso IX, rey de León y de Galicia (1188-1230), repoblador de A Coruña (1208)", en Alfonso IX y su época. Pro utilitate regni mei, A Coruña, Ayuntamiento de A Coruña y Ministerio de Cultura, 2008, págs. 27-28.
} 
por Galicia, sobre la que más adelante volveré y de la que ya habló Gregoria Cavero $^{26}$.

En mi opinión, cuando se examina la concesión de Alfonso IX al hospital de Santa María de O Cebreiro a la luz de todos estos acontecimientos y de un contexto general en el que se observa con claridad cómo el monarca leonés realzó por multitud de acciones el protagonismo de Galicia y las peregrinaciones a Santiago, se entiende mucho mejor el motivo por el cual se desarrolló esta confirmación de privilegios de marzo de 1186.

Un segundo momento mucho más difuso ante la parquedad de detalles del documento tiene lugar a mediados del siglo XVIII cuando, en 1760, se realizó la primera copia del privilegio de Alfonso IX. En esta ocasión, el hospital de peregrinos de Santa María de O Cebreiro aparece vinculado a San Benito de Valladolid.

Fundado este monasterio vallisoletano en 1390 bajo el reinado de Juan I de Castilla, en 1431 se había creado la congregación que estaba llamada a controlar la mayoría de centros benedictinos castellanos a lo largo de la Edad Moderna ${ }^{27}$. Así, en palabras de Ernesto Zaragoza,

La Congregación Observante de Valladolid, poco a poco llegó a reunir el resto de las abadías de España, aunque casi todas estaban situadas en su mitad norte, a saber en Galicia: San Martín Pinario y San Payo de Antealtares de Santiago de Compostela, San Juan de Poyo, San Salvador de Lérez, San Pedro de Tenorio, San Salvador de Celanova, San Esteban de Ribas de Sil, San Vicente del Pino de Monforte de Lemos, San Julián de Samos y San Salvador de Lorenzana $^{28}$.

En el caso concreto de Santa María de O Cebreiro, José García Oro y María José Portela han señalado cómo dicha anexión a la institución vallisoletana se produjo en agosto de 1487, recibiendo a partir de este momento suma atención por parte de los Reyes Católicos como antesala de Compostela ${ }^{29}$. Si tenemos en cuenta

\footnotetext{
${ }^{26}$ Gregoria Cavero Domínguez, "Alfonso IX y la Iglesia de su reino”, en Alfonso IX y su época..., pág. 89 .

27 Sobre los primeros años de este monasterio, v. César Olivera Serrano, "Devociones regias y proyectos políticos: los comienzos del monasterio de San Benito el Real de Valladolid (1390-1430)", Anuario de Estudios Medievales, 43/2 (2013), págs. 799-832.

28 Ernesto Zaragoza Pascual, "Fernando el Católico y la reforma de los benedictinos y benedictinas españoles (1474-1516)", Anuario de Historia de la Iglesia, 26 (2017), págs. 164-165.

29 José García Oro y María José Portela Silva, “Santiago de Compostela, meta de peregrinación: génesis documentales y fuentes archivísticas", en Agustín Hevia Ballina (coord.), Memoria ecclesiae, XVIII. Peregrinación y santuarios en los archivos de la Iglesia, Madrid, Asociación de Archiveros de la Iglesia en España, 2001, pág. 59.
} 
los datos que proporciona Ernesto Zaragoza, parece claro que, entre finales del siglo XV y comienzos del siglo XVI, el nexo entre ambos lugares era relativamente fuerte cuando se examina a personas como Juan de Soria -abad en Valladolid entre 1485 y 1488 y prior de O Cebreiro entre 1517 y 1521 - o como su sucesor Juan de San Juan de Luz, habitual visitador de los monasterios gallegos ${ }^{30}$.

Prescindiendo aquí de la relación entre Santa María de O Cebreiro y de San Benito de Valladolid durante los siglos XVI y XVII a fin de no apartarnos excesivamente del tema, los motivos que subyacen tras la copia dieciochesca del privilegio de Alfonso IX no quedan nada claros. Arrojando nuestra mirada al propio documento, en él no se hace la menor alusión a por qué motivo se realizó, recién iniciado el reinado de Carlos III, una copia de algo que tenía ya más de medio milenio de antigüedad.

No cabe duda de la inmensa labor de erudición que tuvo lugar a lo largo de la Edad Moderna en el seno de la congregación de San Benito y, por extensión, en los centros religiosos que supervisaba. El inmenso patrimonio bibliográfico que custodiaba esta institución ha sido puesto de manifiesto por varios autores y, en especial, por Covadonga Matos, en cuya tesis doctoral, dedicada a las lecturas y libros en el Valladolid del siglo XVIII, dedica una extensísima sección a hablar de la biblioteca de dicha institución ${ }^{31}$.

La lectura y elaboración de escritos es pues algo inherente a cualquier comunidad monástica y, en el caso que nos ocupa, más todavía si cabe si se tiene en cuenta que en 1760, año de la elaboración de la primera copia del privilegio de Alfonso IX, el general de la congregación de San Benito era el gallego fray José Balboa quien, citando una vez más a Ernesto Zaragoza, anima a todos al estudio de la diplomática y a la catalogación de los archivos monásticos ${ }^{32}$.

Con todo, por mucho que se promovieran los estudios diplomáticos en el seno de la congregación, en mi opinión la copia de 1760 no tiene mucho que ver con la erudición, sino más bien con lo que Luis Rodríguez definió, quizá exageradamente, como la susceptibilidad y hasta la persecución por parte de los Borbones que llevó a los benedictinos a justificary defender su postura presentando informes con todo detalle de las rentas y gastos de la Orden ${ }^{33}$.

\footnotetext{
${ }^{30}$ Ernesto Zaragoza Pascual, "Abadologio del monasterio de San Benito el Real de Valladolid (13901835)", Investigaciones históricas. Épocas moderna y contemporánea, 23 (2003), págs. 211-212.

31 Covadonga Matos Eguiluz, Las lecturas y los libros en Valladolid (siglo XVIII) [tesis doctoral presentada en la Universidad de Valladolid], disponible en < http://uvadoc.uva.es/handle/10324/11157 > [Consulta: 04/04/2018]. Muy acertadamente, la autora contextualiza la erudición benedictina vallisoletana con la que se estaba produciendo a nivel europeo, en especial con los trabajos de Jean Mabillon.

32 Ernesto Zaragoza Pascual, Los generales de la Congregación de San Benito de Valladolid. Vol. V: (1701-1801), Burgos, Abadía de Santo Domingo de Silos, 1984, pág. 169.

33 Luis Rodríguez Martínez, Historia del monasterio de San Benito el Real de Valladolid, Valladolid, Caja de Ahorros Popular y Ateneo, 1981, págs. 333-334.
} 
Efectivamente, como abordaré con más detalle a continuación cuando hable del tercer momento histórico que aparece en el documento, la expedición de esta copia de 1760 guarda estrecha relación con la progresiva cristalización de unos ideales ilustrados que abogaban por la introducción de importantes reformas económicas (o por lo menos, por su intento de ejecución) que chocaban frontalmente con los regímenes de propiedad existente en el Antiguo Régimen.

No puedo detallar las medidas impulsadas en España por la monarquía borbónica a lo largo del siglo XVIII ni mucho menos entrar a valorar su acierto o su fracaso. En todo caso, sí resulta crucial destacar cómo muchas de ellas pretendieron fomentar la agricultura como forma de dinamizar la economía y, en el caso de Galicia, los Borbones encontraron no pocos obstáculos puesto que, como afirmaba Antonio Domínguez, allí la mayoría de la tierra pertenecía a la Iglesia y a unas cuantas casas nobles ${ }^{34}$.

Siguiendo a este historiador sevillano, en este contexto, el clero regular fue la bête noire de los reformistas ${ }^{35}$ al considerar muchos de éstos que aquél suponía un freno al dinamismo que intentaban implantar. Es por ello por lo que durante los reinados de Fernando VI y de Carlos III encontramos diversas disposiciones para apartar al clero regular en sus funciones de administradores de tierras, como deja muy claro una real cédula de junio de 1764 en que les autorizó para ejercer ministerios espirituales, pero no dirigir los trabajos agrícolas, del mismo modo que también se les prohibía la administración de herrerías, molinos, fábricas de papel y otras industrias que poseían algunos monasterios ${ }^{36}$.

Ante la ausencia de una mención expresa en el documento a los motivos por los cuales se elaboró la copia de 1760 , no se pueden hacer más que conjeturas, máxime también si se tiene en cuenta que en el trabajo de Lorenzo Maté sobre los fondos archivísticos de la congregación vallisoletana no se contiene ningún dato sobre documentos del Cebreiro ${ }^{37}$, por lo que las relaciones entre ambos lugares más allá de los momentos iniciales se convierten en un misterio. Con todo, creo que las razones apuntadas hasta aquí pueden estar en la buena dirección.

\footnotetext{
${ }_{34}$ Antonio Domínguez Ortiz, Carlos III y la España de la Ilustración, Madrid, Alianza Editorial, 1988, pág. 129.

35 Ibíd., pág. 150.

${ }^{36}$ Ibíd., pág. 151. La explicación de Antonio Domínguez es tremendamente esclarecedora cuando habla de este problema. Así, en esta misma página, indica que no eran populares los monacales; en el medio rural vivian empeñados en frecuentes pleitos con sus colonos. Las largas y extenuadoras horas de coro que constituían su principal ocupación parecian un esfuerzo inútil en una época dominada por criterio de utilidad.

37 Lorenzo Maté SAdornil, “Archivo de la Congregación de San Benito de Valladolid (1500-1835)”, en Agustín Hevia Ballina (coord.), Memoria ecclesiae, VI. Órdenes monásticas y archivos de la Iglesia (I), Madrid, Asociación de Archiveros de la Iglesia en España, 1995, págs. 313-332.
} 
Más sencillo resulta contextualizar el tercer momento relacionado con la historia de este documento, que es la copia de septiembre de 1813, gracias a la cual conocemos los dos diplomas anteriores que en ella se contienen. Parca también en detalles, lo cierto es que se deja perfectamente claro que se realizó a petición del prior de la comunidad, fray José de Castro, y ante el ayuntamiento constitucional de la villa, nueva autoridad municipal so color de la Constitución de Cádiz de 1812 y de escasa vida si tenemos en cuenta la proximidad de la llegada de Fernando VII a España y la anulación de los presupuestos ideológicos gaditanos a partir de 1814 .

Si la copia del privilegio de Alfonso IX realizada en 1760 dejaba entrever una situación delicada para los religiosos de Santa María de O Cebreiro ${ }^{38}$, el periodo comprendido entre 1808 y 1813 no resultó sencillo para las órdenes monásticas como producto de la Guerra de la Independencia y por producirse, siguiendo a Germán Rueda, toda una serie de disposiciones legales que favorecían la enajenación, privatización y venta en pública subasta de los bienes de las órdenes militares, las temporalidades de los jesuitas y de los pertenecientes a los conventos y monasterios suprimidos o destruidos durante la guerr $a^{39}$.

Aunque esto suponga irse a 1821, esto es a pleno Trienio Liberal, Ramón Villares destaca cómo el monasterio orensano de San Pedro de Ramirás también experimentaba dificultades porque los que trabajaban las tierras que dependían de esta institución néganse a pagar a renda a non ser que o mosteiro presente "os títulos primordiais da adquisición destas facendas" 40 .

Ante todo este conjunto de circunstancias claramente desfavorables desde su perspectiva para unas instituciones sobre las que se cernía la sombra de una desamortización por la que se exponían a dejar de percibir los ingresos que las habían sustentado durante siglos enteros, se comprende a la perfección la acuciante necesidad de rastrear en el pasado, aunque fuera el más remoto, para buscar los privilegios y los títulos de propiedad cuya posesión era fundamental demostrar en esta época.

\footnotetext{
38 Además de lo que ya he comentado, resulta interesante la visión de Ramón Villares cuando afirmaba cómo os recursos económicos do clero-especialmente do regular-escomenzaron a sofrir, dende os derradeiros anos do XVIII e ainda mais cando contra dos franceses, unha serie de dificultades que ian dende a crítica "ilustrada" á súa condición de "mans mortas", até a resistencia dos campesiños a pagar ás rendas ou as urxencias do fisco real pra hacer frente ás súas necesidades bélicas: v. Ramón VILLARES PAz, Foros, frades e fidalgos. Estudios de historia social de Galicia, Vigo, Edicións Xerais de Galicia, 1982, pág. 53.

${ }^{39}$ Germán Rueda Hernanz, España 1790-1900. Sociedad y condiciones económicas, Madrid, Istmo, 2006, pág. 130.

${ }^{40}$ Ramón Villares Paz, Desamortización e réxime de propiedade, Vigo, A Nosa Terra, 1994, pág. 47.
} 
En el caso del hospital de peregrinos de Santa María de O Cebreiro, ese pasado remoto lo encontró a finales del siglo XII, en época de los reyes de León Fernando II y Alfonso IX.

\section{¿Alfonso IX EN 1186? REFLEXIONES ACERCA DE LA AUTENTICIDAD DEL DOCUMENTO}

Hay una cuestión absolutamente ineludible que debe tratarse con cierto detenimiento antes de pasar a la edición del documento y que consiste en lo siguiente: ¿por qué aparece Alfonso IX actuando como rey y tomando la iniciativa en 1186 cuando todavía vivía su padre? No cabe duda de que este detalle podría interpretarse como un indicio de falsedad o, cuando menos, como producto de una datación incorrecta; sin embargo, trataré de demostrar a continuación que no me parece que se trate de ninguna de las dos cosas.

En primer lugar, cabe advertir que las tradicionales colecciones diplomáticas de los monarcas castellano-leoneses pertenecientes a los siglos XII y XIII se han centrado en los documentos correspondientes a estos reyes exclusivamente a partir del momento en el que ya tenían la corona en solitario.

Así por ejemplo, las que realizó Julio González dedicadas a los monarcas leoneses Fernando II (1157-1188) y Alfonso IX (1188-1230); a los castellanos Alfonso VIII (1158-1214) y Enrique I (1214-1217) y al castellano-leonés Fernando III (1217-1252) se centran únicamente en sus años de reinado sin tratar, por lo menos en lo que a edición de fuentes se refiere, los periodos relativos a sus épocas como infantes ${ }^{41}$.

Por su parte, exactamente lo mismo sucede en el caso de Sancho IV con la colección documental que le dedicó Mercedes Gaibrois, que únicamente contiene el periodo comprendido entre la muerte de su padre en abril de 1284 y la suya propia en el mismo mes de $1295^{42}$, cuando Manuel González y Ma Antonia Carmona han puesto de manifiesto la existencia de más de trescientos documentos que Sancho expidió entre 1269 y 1284 cuando todavía era infante ${ }^{43}$.

Si parece evidente pues que todo este conjunto de colecciones diplomáticas no resultan de utilidad para estudiar las acciones de todos estos monarcas cuando eran infantes, no es menos claro que todos ellos ejercieron destacadas labores de

\footnotetext{
${ }^{41}$ Además de los ya citados trabajos de este autor sobre Fernando II y Alfonso IX, v. también Julio GoNzÁLez GonzÁlez, El reino de Castilla en la época de Alfonso VIII, Madrid, Consejo Superior de Investigaciones Científicas y Escuela de Estudios Medievales, 1960, donde se incluye también a Enrique I y Julio González González, Reinado y diplomas de Fernando III, Córdoba, Monte de Piedad y Caja de Ahorros de Córdoba, 1980-1986, 3 vols.

${ }^{42}$ Mercedes Gaibrois de Ballesteros, Historia del reinado de Sancho IV de Castilla, Madrid, Tipografía de la Revista de Archivos, Bibliotecas y Museos, 1922-1928, 3 vols.

43 González Jiménez y Carmona Ruiz, Documentación e itinerario..., págs. 653-700.
} 
gobierno en este periodo y se intitularon en muchas ocasiones ya como reyes cuando sus progenitores todavía lo eran.

Centrando nuestra mirada en el siglo XII, Alfonso VII, que no alcanzó la corona en solitario hasta 1126, aparece ya actuando junto a su madre, la reina Urraca, en marzo de 1112 en la donación de la ciudad de Oviedo y otros términos a la iglesia de San Salvador ${ }^{44}$ e incluso desde 1124 el hijo suele anteceder a la madre en las intitulaciones, bien mediante una compartida (A. et. U. Dei gratia Hispaniae Rex et Regina, en un diploma de este mismo año ${ }^{45}$ ) o bien mediante fórmulas individualizadas como en uno de julio de 1125: ego Aldefonsus, Dei gratia imperator Yspanie, una cum dompna Urracha regina, genitrice mea... ${ }^{46}$.

En las postrimerías del reinado de Alfonso VII y aunque éste estuviera plenamente operativo hasta su muerte ${ }^{47}$, observamos a Fernando II ya actuando mientras su padre estaba vivo, tal y como demuestra un documento de julio de 1155 en el que, intitulándose como Legionis et Gallecie rex, confirmó a su capellán, Rodrigo Menéndez, la posesión del monasterio de San Lorenzo, en tierra de Caldelas, cerca del río $\mathrm{Sil}^{48}$.

En resumidas cuentas, aunque los ejemplos no sean tampoco muchos, se observa cómo, tanto en el ámbito castellano-leonés como en el aragonés, era relativamente frecuente que los infantes llevaran a cabo diversas acciones mientras sus progenitores todavía vivían y que éstos aparezcan en los documentos utilizando ya, anticipadamente si se quiere, el título de rex.

De todos los que pertenecieron al siglo XII, el más desconocido en este aspecto en su etapa de infante es, sin ninguna duda, Alfonso IX, puesto que la colección documental que le dedicó Julio González comienza en 1188, mientras que la relación de regestas que este mismo autor realizó sobre su padre no contiene ningún diploma que nos muestre a este rey actuando a iniciativa suya antes de la muerte de Fernando II. Quizá por este motivo, los trabajos que versan sobre Al-

\footnotetext{
${ }_{44}$ Monterde Albiac, Diplomatario..., págs. 64-71. Se trataría éste del primer documento cuyo contenido conocemos en el que se cita al futuro Alfonso VII como filio meo rege domno Alfonso, si bien Cristina Monterde menciona uno anterior, de abril de 1111, cuyo texto se desconoce y por el cual ambos donaron a la iglesia de San Salvador de Irago la ermita de San Cristóbal de Noceda, en el Bierzo (pág. 53).

45 Ibíd., pág. 288. Copio textualmente la transcripción de la intitulación que realizó Cristina Monterde y, por ese motivo, figuran aquí las iniciales de los nombres de los monarcas sin desarrollar y Rex et Regina empezando por mayúscula.

${ }^{46}$ Ibíd., págs. 299-301.

47 Sirva como muestra el tratado que el rey firmó en mayo de 1157 con Ramón Berenguer IV para acordar un nuevo reparto de Navarra: v. Manuel Recuero AstraY, Alfonso VII (1126-1157), Burgos, La Olmeda, 2003, pág. 300.

48 Recuero Astray, Romero Portilla y Rodríguez Prieto, Documentos medievales..., págs. 3-4.
} 
fonso IX suelen tener como horizonte cronológico el año 1188, no remontándose por lo general más allá de esta fecha ${ }^{49}$.

La actuación por lo tanto de Alfonso IX antes de su coronación es una cuestión por lo tanto apenas explorada por los investigadores, habida cuenta de que, por otra parte también, los testimonios son casi inexistentes. Tan sólo puede resaltarse una concesión foral que hizo a Mansilla de las Mulas (León) en marzo de $1181^{50}$, puesto que una declaración de protección a los ganados del monasterio de Santa María de Gradefes de junio de 1187 que Taurino Burón atribuyó a Alfonso IX se trata en realidad de Alfonso VIII de Castilla ${ }^{51}$.

Como es previsible, habidas las circunstancias, el diploma de Mansilla de las Mulas ha levantado serias sospechas sobre su autenticidad. Así, José Ignacio González afirmaba que

el documento presenta un serio problema de datación, pues es imposible que Alfonso IX otorgase un fuero a Mansilla en la fecha citada, es decir siete años antes de llegar al trono, por lo que o bien hay un error en el monarca, tratándose en realidad de Fernando II, o en la fecha, o el documento es falso ${ }^{52}$.

No quiero enjuiciar la autenticidad o falsedad de este diploma relativo a Mansilla de las Mulas, pero, a mi entender y al margen de sus peculiaridades paleográficas y diplomáticas, creo que no deben considerarse falsos únicamente porque pertenezcan a momentos anteriores a 1188 cuando se ve cómo, a lo largo del siglo XII, esto no era para nada algo atípico y ya se habían producido antecedentes de infantes actuando por su propia iniciativa y utilizando la denominación de rex.

En mi opinión, el caso de Mansilla de las Mulas es relativamente parecido al del hospital de peregrinos de Santa María de O Cebreiro si se tiene en cuenta que

\footnotetext{
49 Además de los que ya he citado, v. otros como Carlos de Ayala Martínez, "Alfonso IX, último monarca del reino de León (1188-1230)" en César Álvarez Álvarez (coord.), Reyes de León: monarcas leoneses del 850 al 1230, León, Edilesa, 1996, págs. 193-216 o Gregoria CAVERo Domínguez, "Alfonso IX de León y el íter de su corte (1188-1230)", E-Spania. Revue électronique d'études hispaniques médiévales [revista electrónica], 8 (2009), disponible en <http://e-spania.revues.org/18626> [Consulta: 19/11/2017].

${ }^{50}$ Mauricio Herrero Jiménez, Colección documental del monasterio de Villaverde de Sandoval (11321500), León, Centro de Estudios e Investigación "San Isidoro", Caja España y Archivo Histórico Diocesano, 2003, págs. 65-66.

51 Taurino Burón Castro, Colección documental del monasterio de Gradefes, León, Centro de Estudios e Investigación "San Isidoro", Caja España y Archivo Histórico Diocesano, 1998, vol. I, págs. 246-247.

52 José Ignacio GonzÁlez Ramos, Villas reales en el reino de León. Los procesos pobladores de Fernando II y Alfonso IX en la tierra de León, León, Centro de Estudios e Investigación "San Isidoro", Caja España y Archivo Histórico Diocesano, 2008, pág. 189.
} 
tan sólo un par de meses antes, en enero de 1181, Fernando II otorgó la carta de población a esta población leonesa ${ }^{53}$.

Por desgracia, los testimonios son tan escasos que no es posible llegar a certezas absolutas, si bien, a mi juicio, nos encontramos en ambos casos ante un padre y un hijo que, además de figurar ambos en la documentación estrechamente ligados y siguiendo la tradición leonesa, actuaban conjuntamente, de manera que cuando uno tomaba alguna decisión el otro la refrendaba en un escaso margen de tiempo.

Si en Mansilla de las Mulas aparece Fernando II otorgando a sus habitantes una carta de población en enero de 1181 y en marzo de ese mismo año Alfonso IX intervenía realizando una concesión foral a la misma comunidad, en Santa María de O Cebreiro podríamos tener una situación parecida con un Alfonso que estaría confirmando en 1186 sus posesiones a los religiosos lucenses, mientras que Fernando lo habría hecho al año siguiente si nos basamos en el hipotético documento de febrero de 1187 del que hablaron el padre Yepes, Elías Valiña y Luis López.

Por otra parte, el documento que ofrezco en este trabajo no pretende en ningún momento engañar ni sugerir que Alfonso IX ya reinara en solitario, porque aparece una mención clara a Fernando II como monarca leonés (Regnante rege Fernando cum filio suo rege / Alfonso Legione, Galecia, Asturiis et Extremisdorii), por lo que queda descartada a mi juicio la posibilidad de que hubiera sido de fecha posterior a 1188 con una data equivocada, puesto que, de haberlo sido, no se hubiera mencionado a Fernando II como alguien que todavía vivía.

Por último, el análisis diplomático detenido del documento no hace más que avalar la autenticidad del mismo, puesto que todas las partes que en él se encuentran coinciden prácticamente de forma exacta en cuanto a formulación y orden de aparición con las que Manuel Lucas ha definido como las típicas de la cancillería de Alfonso IX ${ }^{54}$.

Empezando por lo que él denomina como formas extrínsecas "intra tenorem”, no encontramos invocación monogramática por tratarse de una copia en la que no se dibujó, si bien sí la típica explícita In nomine Domini nostri Iesuchristi, /

\footnotetext{
${ }^{53}$ V. una transcripción de la misma en Isidoro González Gallego, Mansilla de las Mulas: origen y desarrollo de una villa leonesa bajomedieval, Valladolid, Ayuntamiento, 1996 y una traducción en Lázaro Álvarez Rodríguez, Mansilla de las Mulas, monasterios y pueblos colindantes, León, Imprenta Casado, 1981, págs. 21-24.

54 Todo lo referente a la estructura documental y a las formas, tanto extrínsecas como intrínsecas, en LuCas Álvarez, El reino de León..., págs. 543-563.
} 
$a^{a m e n^{55}}$. La datación ${ }^{56}$ también encaja con lo que observamos cuando se examina el conjunto de documentación de Alfonso IX, iniciándose con la cláusula Facta carta apud y siguiendo con la localidad, el año según el sistema de la Era Hispánica y el mes y el día según la tradición romana.

Por otra parte, Lucas señala cómo, a diferencia de durante Alfonso VII y Fernando II, con Alfonso IX desaparece el año de reinado, mientras que la expresión Regnante rege queda circunscrita a los primeros momentos $\mathrm{y}$, en concreto, a las cancillerías de Pedro Vélez y del deán don Fernando ${ }^{57}$. Todo esto coincide plenamente con el privilegio de 1186, en el cual aparece el susodicho Pedro Vélez identificado como canciller: per / manum domini Petri Velez, cancilari.

La intitulación del documento de $\mathrm{O}$ Cebreiro tampoco difiere de las típicas de un monarca que ya no utilizará el título de Hispaniarum rex, tal y como habían hecho sus predecesores. Manuel Lucas indica cómo hasta mayo de 1189 Alfonso IX no incluyó Galicia en sus intitulaciones, apareciendo en los primeros documentos únicamente León ${ }^{58}$. La utilización de la fórmula Dei gracia rex Legionis que aparece en nuestro caso, sin mencionar todavía a Galicia, permitiría validar también la fecha o, cuando menos, el espectro cronológico en el que fue redactado.

Por otra parte, también hay coincidencia plena en lo que se refiere a la estructura típica de los inicios de los diplomas de Alfonso IX, con un exordio introductorio y una intitulación que aparecen enlazados con expresiones tales como idcirco, ideo, quare o, como en el caso del privilegio a Santa María de O Cebreiro, ea propter.

Aunque a mi juicio todos estos elementos son ya de por sí suficientes para avalar la autenticidad del documento que tenemos delante, ésta queda ratificada cuando se examinan los motivos por los cuales Manuel Lucas consideraba que determinados diplomas de Alfonso IX de los recogidos en la colección de Julio González podían considerarse falsos.

Así, según este autor, eran indicios de falsificación o, cuando menos, de sospecha la presencia en la lista de confirmantes de personas que no correspondían a la época, el hecho de que un mismo asunto se repitiera poco tiempo después,

\footnotetext{
${ }^{55}$ Las hago constar tal y como aparecen escritas en el documento que yo he manejado, esto es, la copia del siglo XIX. Es posible que algunas incorrecciones en el uso de las palabras latinas no se encontraran en el original.

${ }_{56}$ Para mi gusto, Manuel Lucas realiza un análisis diplomático bastante confuso al no seguir el orden en el que va apareciendo cada elemento dentro del documento. En todo caso, y puesto que me baso en su trabajo que considero el mejor sobre la cancillería de Alfonso IX, respetaré su criterio e iré analizando las fórmulas del de Santa María de O Cebreiro en el mismo orden en el que él trató esta cuestión al hablar en general.

57 Ibíd., pág. 546.

58 Ibíd., pág. 547.
} 
la inclusión de fórmulas más propias de otros momentos o la aparición de un signo real rodado que no encajara tampoco con el periodo ${ }^{59}$.

Con excepción de este último detalle que no se puede comprobar en el de $\mathrm{O}$ Cebreiro por tratarse no del original sino de una copia, ninguna de las circunstancias enumeradas que inducen a sospecha se produce en el de 1186, por lo que, a tenor de todo esto, no existe ningún motivo para dudar de la autenticidad del documento que tenemos entre manos.

\section{SignifiCAdo DEL PRIVILEGIO DE 1186 EN EL REINADO DE AlFonso IX}

No tiene sentido demorar la respuesta sencilla y contundente que surge cuando nos preguntamos qué importancia tuvo este privilegio para el reinado posterior de Alfonso IX: absolutamente ninguna.

Por un lado, como ya he adelantado, está completamente fuera de duda, si tenemos en cuenta la documentación, que Galicia fue el lugar en el que más veces estuvo Alfonso IX, tal y como expresaba rotundamente Gregoria Cavero al hablar del escenario gallego en la vida del rey:

Fue, sin duda, el más practicado por el monarca, especialmente en los años centrales de su reinado. Recordemos que alli se encontraba cuando murió Fernando II; en Galicia se armó caballero y en Galicia, en Compostela, acabó siendo sepultado. Es precisamente esta ciudad aquella en que más tiempo permaneció el monarca, allí donde acudió a la consagración de la catedral; y allí donde celebró algunas curias: la que tuvo lugar en la primavera de 1211 allí se reunió. Y en el castillo de Sarria falleció a fines de septiembre de $1230^{60}$.

Tampoco puede dudarse de las buenas relaciones que Alfonso IX mantuvo con la Iglesia en general y con los monasterios gallegos en particular. Además de algunos estudios específicos que así lo recalcan ${ }^{61}$, la colección diplomática que de este monarca elaboró Julio González nos muestra cómo un poco más del 20\%

\footnotetext{
${ }^{59}$ Ibíd., págs. 506-508.

${ }^{60}$ Cavero Domínguez, “Alfonso IX de León y el íter...”. Se trata de una publicación electrónica que no tiene números de página, por lo menos en su versión web.

${ }^{61}$ V., por ejemplo, José Luis LóPez SANGIL, "Privilegios reales concedidos por Alfonso VII, Fernando II y Alfonso IX al monasterio de Santa María de Monfero: años 1135 a 1213", Cátedra: revista eumesa de estudios, 5 (1998), págs. 107-146 o Luis Rodríguez EnNEs, “Cinco privilegios monásticos confirmados por Alfonso IX de León y Galicia en tierras de Laxe (A Coruña) el 25 y 26 de julio de 1228”, GLOSSAE. European Journal of Legal History, 14 (2017), págs. 786-804.
} 
de su producción documental consistió en privilegios a instituciones monásticas gallegas, según las cifras que indico a continuación ${ }^{62}$ :

\begin{tabular}{|l|l|l|}
\hline \multicolumn{1}{|c|}{ MonASTERIO } & \multicolumn{1}{c|}{$\begin{array}{c}\text { CANTIDAD DE } \\
\text { DOCUMENTOS }\end{array}$} & \multicolumn{1}{c|}{ MARCO TEMPORAL } \\
\hline Santa María de Sobrado & 22 & $1189-1228$ \\
\hline Santa María de Melón & 19 & $1193-1230$ \\
\hline San Justo de Tojos Outos & 12 & $1198-1228$ \\
\hline San Salvador de Celanova & 11 & $1216-1228$ \\
\hline Santa María de Meira & 10 & $1191-1227$ \\
\hline San Esteban de Ribas de Sil & 10 & $1213-1220$ \\
\hline Santa María de Montederramo & 8 & $1210-1229$ \\
\hline Santa María de Oya & 7 & $1198-1228$ \\
\hline Santa María de Osera & 6 & $1207-1228$ \\
\hline San Martín de Fora / Pinario & 6 & $1206-1228$ \\
\hline San Vicente de Monforte & 5 & $1199-1218$ \\
\hline San Julián de Samos & 2 & $1190-1195$ \\
\hline San Lorenzo de Carboeiro & 2 & $1192-1214$ \\
\hline San Salvador de Asma / Chantada & 2 & 1208 \\
\hline San Miguel de Couselo & 1 & 1206 \\
\hline Santa María de Ferreira de Pallarés & 1 & 1209 \\
\hline San Esteban de Chouzán & 1 & 1213 \\
\hline Santa María de Monfero & 1 & 1213 \\
\hline San Juan de Caaveiro & 1 & 1214 \\
\hline Santa María de Ferreira de Pantón & 1 & 1215 \\
\hline San Claudio de Ourense & 1 & 1218 \\
\hline San Salvador de Bergondo & 1 & 1218 \\
\hline Santa María de Penamaior & 1 & 1227 \\
\hline Santa María de Xunqueira de Espanedo & 1 & 1227 \\
\hline San Lorenzo de Sinapale (Fiabal) ${ }^{63}$ & 1 & 1228 \\
\hline San Payo de Antealtares & 1 & 1228 \\
\hline San Salvador de Cines & 1 & 1229 \\
\hline Santa Comba de Naves & 1 & 1229 \\
\hline San Pedro de Rocas & Sin fecha \\
\hline & & \\
\hline & 1 & \\
\hline & & \\
\hline
\end{tabular}

Salta a la vista que Santa María de O Cebreiro no se encuentra en el listado anterior. No obstante, si centramos nuestra mirada en esta institución, su relación con la monarquía a lo largo del tiempo es incuestionable. Así, según Ernesto Zaragoza, en el Archivo Histórico Nacional hay un índice de documentos relativos a

\footnotetext{
${ }^{62}$ Las cifras que ofrezco proceden de un recuento propio.

${ }^{63}$ La aclaración de Fiabal procede de Manuel PÉrez Villamil, "El señorío temporal de los obispos de España”, Boletín de la Real Academia de la Historia, LXVIII (1916), pág. 385.
} 
este monasterio en el que consta cómo Pedro I, Juan I, Enrique III y Juan II confirmaron a los religiosos sus privilegios en diversos momentos, mientras que Enrique II declaró a sus vecinos exentos del pago de pechos y derechos en $1373^{64}$.

Resumiendo, existe abundante documentación tanto de Alfonso IX como del hospital de Santa María de O Cebreiro, pero lo cierto es que, tras 1186, ambos siguen caminos separados y en ningún momento se cruzan. La clave no está pues en buscar el significado que dicho privilegio tuvo para el reinado del monarca, sino, como he reiterado abundantemente, en entender la importancia que tuvo el hecho de que lo hiciera antes de serlo una vez que puede apostarse por su autenticidad.

\section{CONCLUSIONES}

Aunque no haya tantos como a partir del siglo XIII, diversos testimonios correspondientes ya al siglo XII permiten rastrear la labor de los infantes de la monarquía leonesa, dimensión ésta no estudiada en unas colecciones diplomáticas que, por lo general, comienzan en los años de reinado y no se adentran en periodos anteriores a su coronación.

En este sentido, Alfonso IX, un monarca al que hasta hace relativamente poco no se le había prestado la atención que merecía en beneficio de otros de sus contemporáneos, aparece en los documentos muy estrechamente ligado a su padre desde su nacimiento. Hasta el momento dos documentos nos lo muestran actuando a iniciativa propia antes de su subida al trono en solitario en 1188: una concesión foral a Mansilla de las Mulas de 1181 y una confirmación al hospital de peregrinos de Santa María de O Cebreiro de 1186.

En lo que se refiere a esta institución gallega, considero que el documento es notablemente importante en tanto en cuanto complementa la colección diplomática que sobre este monarca leonés publicó Julio González en 1944, además de que da a conocer una fuente histórica cuyo original había desaparecido.

Reaparecido gracias a una copia realizada bajo unas circunstancias históricas muy diferentes al momento en que se redactó dicha confirmación de privilegios, no cabe ninguna duda del inmenso valor que tiene la documentación de las Edades Moderna y Contemporánea para encontrar testimonios de la Edad Media que se creían perdidos.

Por todo este conjunto de motivos, esto es, porque no afecta sólo a la historia de Galicia, sino porque permite extenderse a otras cuestiones muy poco estudiadas dentro de la monarquía hispana del siglo XII, como es el papel de los infantes al lado de sus padres, es por lo que considero esta confirmación de privilegios al

\footnotetext{
${ }^{64}$ Ernesto ZaRAGOZa PaScual, "Índice documental de los monasterios benedictinos de Monforte, Chantada, Cebrero y Moraime (ss. IX-XVIII)”, Diversarum rerum, 8 (2013), pág. 239.
} 
hospital de peregrinos de Santa María de O Cebreiro como un documento de gran valor que merece una publicación en exclusiva. En mi opinión, tratarlo en relación a otros temas hubiera supuesto restarle singularidad y difuminar los aspectos que he querido resaltar.

\section{NORMAS DE TRANSCRIPCIÓN, ADVERTENCIAS Y APÉNDICE DOCUMENTAL}

No existen hoy en día unas normas de transcripción que sean aceptadas por todos los historiadores, paleógrafos y diplomatistas, sino más bien numerosas variantes propuestas a lo largo del tiempo por diversos especialistas en la materia ${ }^{65}$. Por este motivo, aplico las que mayor aceptación han tenido, como son las aprobadas en 1984 por la Comisión Internacional de Diplomática y resumidas por Isabel García en un manual de reciente publicación ${ }^{66}$.

Básicamente, propugnan el máximo respeto al texto original en lo que se refiere a la transcripción de palabras, que no en cuanto a signos de puntuación o separación por párrafos. En este sentido, la copia del siglo XIX que he manejado contiene numerosas incorrecciones en determinadas palabras latinas tales como autoritate, dapnum, cancilari, propias en vez de proprias..., lo que puede dar al lector la sensación de que se trata de errores de transcripción.

Tras una concienzuda revisión, no lo son por mi parte, excepto en aquellos casos en donde yo mismo he indicado la lectura dudosa con un interrogante. Allá donde los errores del copista llaman más la atención o en donde las palabras latinas se alejan más de las formas clásicas, he optado por indicar la advertencia ( $\mathrm{sic}$ ), como recomiendan las normas.

Igualmente, en connivencia con ellas, los corchetes indican lecturas hipotéticas, la raya oblicua (/) señala cambio de línea, la doble raya oblicua (//) se refiere a un cambio de folio y los signos $<>$ contienen en su interior fragmentos interlineados.

En cuanto a los documentos de la Edad Moderna, las normas permiten introducir adaptaciones de los criterios dados para documentos medievales. Es el caso de las tildes que figuran en los documentos 2 y 3 y que, aunque den sensación de erráticas, se corresponden con aquellas palabras que las contienen en la copia del siglo XIX.

\footnotetext{
${ }_{65}$ Sobre la evolución de las normas de transcripción y su enorme disparidad, v. José Miguel LóPEZ VILLALBA, "Normas españolas para la transcripción y edición de colecciones diplomáticas", Espacio, tiempo y forma. Serie III, Historia medieval, 11 (1998), págs. 285-306.

${ }^{66}$ Isabel García DíAz, "Crítica textual y edición de textos", en Juan Carlos Galende Díaz, Susana Cabezas Fontanilla y Nicolás Ávila Seoane (coords.), Paleografia y escritura hispánica, Madrid, Síntesis, 2016, págs. 325-330.
} 
1186, marzo, 30. León.

Alfonso IX, rey de León, declara su protección al hospital de Santa María de O Cebreiro, le confirma los cotos que le había concedido su padre Fernando II en Zanfoga, Pereje, Santa María de Bercianos y Riocereixa; permite a sus ganados la libertad de pasto y declara exentas de la fiscalidad regia a unas casas que el hospital poseía en Villafranca.

A CORUÑA, Documento inserto en Arquivo de la Real Academia Galega, Depósito 1, caixa 547 , 17. Papel, copia del siglo XIX, castellano, escritura humanística, 2 hojas, $32 \times 22 \mathrm{~cm}$.

In nomine Domini nostri Iesuchristi, / amen.

Ne presentis etatis facta consumat oblivio pagi/narum debet iudiciis eternari, ea propter ego Alfonsus, / Dei gracia rex Legionis, autoritate patris mei regis / Fernandi, pro remedio anime mee et parentum meorum / [hoc] factum perpetuo valiturum recipio in comenda et defen/[si]one mea hospitale Sancte Marie de Monte Cebruario / (roto)t omnia iura ad eum pertinencia, tam domos quam / hereditatus ( $\mathrm{sic}$ ), tam vis mobiles quam inmobiles, in regno pa/tris mei et meo constitutas ut nullus in eis deinceps dap/num vel iniuriam facere presumat.

Concedo etiam pre/libato hospitali Sancte Marie de Monte Cebruario et // confirmo omnes cautos quos ei pate[r meus r] ex Fer/nandus et ceteri predecesores mei conceserunt et confirmaverunt.

Concedo preterea et confirmo cautum de Centumfoca et de Perex et cautum domorum de Villa/franca ac predictum ospitale penintentium.

Cautum / etiam Sancte Marie de Vercianos et fluminis de Cires que / pater meus constituit et confirmavit concedo et confir/mo.

Cauto denique iumenta pretaxati hospitalis que / usibus pauperum deferunt necesaria ut libere et qui/ete eant et redeant per totum regnum patris mei / et meum.

Livero etiam Deo et Sancte Marie iam/dicti hospitalis propias ( $\mathrm{sic}$ ) domos quas in Villafranca po/sidet ipsum hospitale ut deinceps sint libere ab omni / fisco facendaria et foro regio in perpetuum.

Si quis igi/tur, tam de meo quam de alieno genere, hoc meum / factum spontaneum inquietare presumpserit, sit / maledictus et excomunicatus et cum Iuda prodictore / in inferno dapnatus et pro aus $[\mathrm{u}]$ temerario parti regis / mille morabetinos pectare cogatus.

Facta carta apud / Legionem, sub era M CC XXIIII, III ${ }^{\circ}$ kalendas / aprilis. 
Regnante rege Fernando cum filio suo rege / Alfonso Legione, Galecia, Asturiis et Extremisdorii.

Ego, rex dominus Alfonsus, hoc scriptum quod aut[o]/ritate patris mei rege Fernandi fieri iussi propio (sic) rob[o]/re confirmo.

Petrus, Compostelanus arciepiscopus, confir/mat. Manricius, Legionensis episcopus, confirmat. Ro/dericus, Ovetensis episcopus, confirmat. Vs. $(\operatorname{sic})^{67}$, Zamorensis / episcopus, confirmat. Vitalis, Salamaticensis episcopus, / confirmat. Petrus, Civitatensis episcopus, confirmat. // Raimundus (sic), Caurensis episcopus, confirmat. Rodericus, Lu/censis <episcopus>, confirmat. Alfonsus, Auriensis episcopus, confirmat. Ra/binatus, Mindoniensis episcopus, confirmat. Bertrandus, / Tudensis episcopus, confirmat.

Comes P., tenens Astu/rias, confirmat. Comes Gomez Trastamerum confirmat. Comes / Fernandus Venabentum confirmat. Veremundus / Alvarez confirmat. Poncius Velez confirmat. Froila / Ramirez confirmat. Petrus Captibus confirmat. / Pelagius Tabladello confirmat. Lupus de Mena confirmat. /

Ego Gondisalbus, domini regis Alfonsi notarius, per / manum domini Petri Velez, cancilari, scripsi.

1760, noviembre, 14. Valladolid.

Francisco Mozo Hernández, escribano del número de Valladolid, realiza una copia de una confirmación de privilegios de Alfonso IX de León al hospital de Santa María de Cebreiro y certifica la validez de la misma.

A CORUÑA, Documento inserto en Arquivo de la Real Academia Galega, Depósito 1, caixa 547, 17. Papel, copia del siglo XIX, castellano, escritura humanística, 2 hojas, $32 \times 22 \mathrm{~cm}$.

Francisco Mozo Hernandez, escribano del rey nuestro / senor del numero perpetuo de esta ciudad de Valladolid, doy / fee que oi dia de la fecha, estando en el real monasterio de San Be/nito de ella y en su archivo por el reverendo padre fray Placido Gomez, / archivero de el, se me exivió un real privilegio de el señor / rey don Alonso el decimo, escrito en pergamino, cuio te/nor es el siguiente:

Concuerda con el original que en latin lo pronuncio segun resul/ta el referido padre predicador fray Placido Gomez, que de ser asi / cierto lo juro in verbo

\footnotetext{
${ }^{67}$ Se refiere al obispo de Zamora en aquel entonces, cuyo nombre era Guillermo. Posiblemente en el original pusiera una "W" como inicial de "Willelmus" y el copista no supo identificar la letra correctamente.
} 
sacerdotis poniendo su mano / derecha sobre su pecho y corona y se quedo en dicho ar/chivo con el original de todo, lo qual firmará aqui.

$\mathrm{Y} /$ para que asi coste (sic), yo, el nominado scrivano, lo signo y firmo / en Valladolid a catorce de noviembre de mil setecientos y / sesenta en estas dos fojas del sello tercero.

Fray Placido / Gomez.

En testimonio de verdad, Francisco Mozo Her/nandez.

1813, septiembre, 23. O Cebreiro.

Ramón Alfaya y Somoza, secretario del ayuntamiento de O Cebreiro, certifica la validez de un documento de 1760 que contenía la copia de una confirmación de privilegios al hospital de Santa María de esta localidad realizada por Alfonso IX en 1186.

A CORUÑA, Arquivo de la Real Academia Galega, Depósito 1, caixa 547, 17. Papel, copia del siglo XIX, castellano, escritura humanística, 2 hojas, $32 \times 22 \mathrm{~cm}$.

(Cruz al centro).

Don Ramon Alfaya y Somoza, escribano de su magestad y secretario / del ayuntamiento constitucional de la villa y juridiccion del Cebrero / doy fe y legal testimonio para que asi conste donde combenga de / extrajudicial mandato del señor alcalde de este juzgado en como / por el padre prior fray Jose de Castro, que lo es de la orden de San Benito / y de la esta villa, me exibio el documento cuyo tenor a la / letra dice asi:

Resulta a continuacion la comprobacion de la firma / [del] escribano Francisco Mozo Hernandez por los que se titulan escribanos del / [nu]mero de la ciudad de Valladolid y llaman Jose de Men/gutia, Tomas Juan Canton y Hipolito Chamochin, / segun aparece certificado por ellos en dicha ciudad / a diez y seis de noviembre de mil setecientos y sesen/ta.

Valga. //

Lo relacionado mas por estenso consta del do/cumento exibido por el padre fray Jose de Castro y lo in/serto dice a la letra con su original a que yo, el / escribano con su (merced?) me remito y volbio recoger dicho / prior.

Y (lac: para) que asi conste lo firmo con dicho señor / alcalde y signo en este pliego del sello que se / reconoce, estando en la villa del Cebrero / a veinte y tres de septiembre de mil ochocientos / trece.

Don Domingo (Armesto?) y Valcarce. Ramon Alfaya Somoza. 


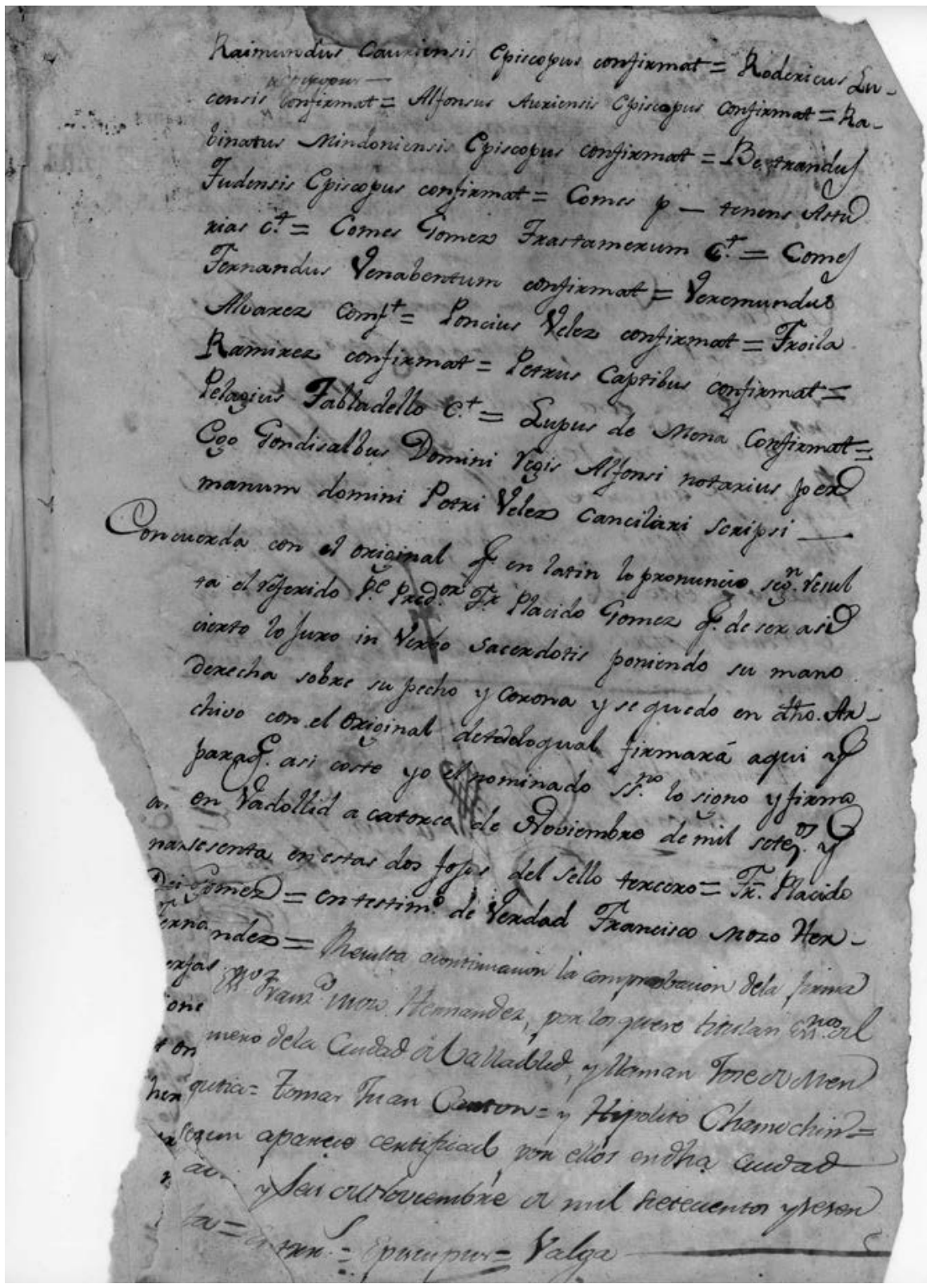

Fuente: Real Academia Galega, depósito 1, caixa 547, 17. 


\section{BIBLIOGRAFÍA}

Álvarez Rodríguez, Lázaro, Mansilla de las Mulas, monasterios y pueblos colindantes, León, Imprenta Casado, 1981.

Ayala Martínez, Carlos de, "Alfonso IX, último monarca del reino de León (1188-1230)" en César Álvarez Álvarez (coord.), Reyes de León: monarcas leoneses del 850 al 1230, León, Edilesa, 1996, págs. 193-216.

Burón Castro, Taurino, Colección documental del monasterio de Gradefes, León, Centro de Estudios e Investigación "San Isidoro”, Caja España y Archivo Histórico Diocesano, 1998.

Calderón Medina, Inés, Cum magnatibus regni mei. La nobleza y la monarquía leonesas durante los reinados de Fernando II y Alfonso IX (1157-1230), Madrid, Consejo Superior de Investigaciones Científicas, 2011.

Cavero Domínguez, Gregoria, "Alfonso IX y la Iglesia de su reino", en Alfonso IXy su época. Pro utilitate regni mei, A Coruña, Ayuntamiento de A Coruña y Ministerio de Cultura, 2008, págs. 89-100.

Cavero Domínguez, Gregoria, "Alfonso IX de León y el íter de su corte (1188-1230)", E-Spania. Revue électronique d'études hispaniques médiévales [revista electrónica], 8 (2009), disponible en < http://e-spania.revues.org/18626 > [Consulta: 19/11/2017].

Celeiro Álvarez, Luis, Elías Valiña, Santiago de Compostela, Xunta de Galicia, 1996.

Cingolani, Stefano $\mathrm{M}^{\mathrm{a}}$, Historia y mito del rey Jaime I de Aragón, Barcelona, Edhasa, 2008.

Comisión Internacional de Diplomática, Falsos y falsificaciones de documentos diplomáticos en la Edad Media, Zaragoza, Real Sociedad Económica Aragonesa de Amigos del País, 1991.

Domínguez Ortiz, Antonio, Carlos III y la España de la Ilustración, Madrid, Alianza Editorial, 1988.

Gaibrois de Ballesteros, Mercedes, Historia del reinado de Sancho IV de Castilla, Madrid, Tipografía de la Revista de Archivos, Bibliotecas y Museos, 1922-1928.

García Díaz, Isabel, "Crítica textual y edición de textos”, en Juan Carlos Galende Díaz, Susana Cabezas Fontanilla y Nicolás Ávila Seoane (coords.), Paleografía y escritura hispánica, Madrid, Síntesis, 2016, págs. 325-330.

García Oro, José y Portela Silva, María José, "Santiago de Compostela, meta de peregrinación: génesis documentales y fuentes archivísticas", en Agustín Hevia Ballina (coord.), Memoria ecclesiae, XVIII. Peregrinación y santuarios en los archivos de la Iglesia, Madrid, Asociación de Archiveros de la Iglesia en España, 2001, págs. 33-85.

González Gallego, Isidoro, Mansilla de las Mulas: origen y desarrollo de una villa leonesa bajomedieval, Valladolid, Ayuntamiento, 1996.

González González, Julio, Regesta de Fernando II, Madrid, Instituto “Jerónimo Zurita”, 1943.

González González, Julio, Alfonso IX, Madrid, Instituto “Jerónimo Zurita”, 1944.

González González, Julio, El reino de Castilla en la época de Alfonso VIII, Madrid, Consejo Superior de Investigaciones Científicas y Escuela de Estudios Medievales, 1960.

González González, Julio, Reinado y diplomas de Fernando III, Córdoba, Monte de Piedad y Caja de Ahorros de Córdoba, 1980-1986.

González Jiménez, Manuel y Carmona Ruiz, María Antonia, Documentación e itinerario de Alfonso Xel Sabio, Sevilla, Secretariado de Publicaciones de la Universidad de Sevilla, 2012.

González Ramos, José Ignacio, Villas reales en el reino de León. Los procesos pobladores de Fernando II y Alfonso IX en la tierra de León, León, Centro de Estudios e Investigación "San Isidoro", Caja España y Archivo Histórico Diocesano, 2008. 
LA RECUPERACIÓN DE UN PRIVILEGIO PERDIDO DE ALFONSO IX AL HOSPITAL DE PEREGRINOS DE SANTA MARÍA DE O CEBREIRO (1186) A PARTIR DE UNA COPIA DEL SIGLO XIX

Herrero Jiménez, Mauricio, Colección documental del monasterio de Villaverde de Sandoval (1132-1500), León, Centro de Estudios e Investigación "San Isidoro", Caja España y Archivo Histórico Diocesano, 2003.

Lalinde Abadía, Jesús, "Reflexiones ante la semblanza de Alfonso X de León y IX de Castilla", Medievalia, 10 (1992), págs. 237-245.

López, Gregorio; Sanponts y Barba, Ignacio; Martí de Eixala, Ramón y Ferrer y Subirana, José, Las Siete Partidas del sabio rey don Alfonso el IX, Barcelona, Imprenta de Antonio Bergnes, 1843-1844.

López Pombo, Luis, O Cebreiro. Apuntamentos históricos e documentais, Lugo, Deputación de Lugo, 2013.

López Pombo, Luis, "Archivo del priorato de Nuestra Señora del Cebreiro (Lugo)”, Estudios de genealogía, heráldica y nobiliaria de Galicia, 12 (2016), págs. 97-181.

López Sangil, José Luis, "Privilegios reales concedidos por Alfonso VII, Fernando II y Alfonso IX al monasterio de Santa María de Monfero: años 1135 a 1213", Cátedra: revista eumesa de estudios, 5 (1998), págs. 107-146.

López Villalba, José Miguel, "Normas españolas para la transcripción y edición de colecciones diplomáticas", Espacio, tiempo y forma. Serie III, Historia medieval, 11 (1998), págs. 285-306.

Lucas Álvarez, Manuel, El reino de León en la Alta Edad Media. Vol V: Las cancillerías reales (1109-1230), León, Centro de Estudios y de Investigación "San Isidoro", Caja España de Inversiones, Caja de Ahorros y Monte de Piedad y Archivo Histórico Diocesano, 1993 (Fuentes y estudios de historia leonesa, núm. 53).

Marichalar, Carlos, Colección diplomática del rey don Sancho VIII (El Fuerte) de Navarra, Pamplona, Aramburu, 1934.

Maté Sadornil, Lorenzo, "Archivo de la Congregación de San Benito de Valladolid (15001835)”, en Agustín Hevia Ballina (coord.), Memoria ecclesiae, VI. Órdenes monásticas y archivos de la Iglesia (I), Madrid, Asociación de Archiveros de la Iglesia en España, 1995, págs. 313-332.

Matos Eguiluz, Covadonga, Las lecturas y los libros en Valladolid (siglo XVIII) [tesis doctoral presentada en la Universidad de Valladolid], disponible en $<$ http://uvadoc.uva.es/handle/10324/11157 > [Consulta: 04/04/2018].

Monterde Albiac, Cristina, Diplomatario de la reina Urraca de Castilla y León (1109-1126), Zaragoza, Anubar, 1996.

Olivera Serrano, César, "Devociones regias y proyectos políticos: los comienzos del monasterio de San Benito el Real de Valladolid (1390-1430)", Anuario de Estudios Medievales, 43/2 (2013), págs. 799-832.

Pérez González, Maurilio, “Originales y copias en la documentación latina medieval”, Minerva. Revista de filología clásica, 3 (1989), págs. 241-275.

Pérez Villamil, Manuel, "El señorío temporal de los obispos de España", Boletín de la Real Academia de la Historia, LXVIII (1916), págs. 361-390.

Recuero Astray, Manuel; Romero Portilla, Paz y Rodríguez Prieto, $\mathrm{M}^{\mathrm{a}}$ Ángeles, Documentos medievales del reino de Galicia: Fernando II (1155-1188), s. 1., Xunta de Galicia, 2000.

Recuero Astray, Manuel, Alfonso VII (1126-1157), Burgos, La Olmeda, 2003.

Recuero Astray, Manuel, "Alfonso IX, rey de León y de Galicia (1188-1230), repoblador de A Coruña (1208)", en Alfonso IX y su época. Pro utilitate regni mei, A Coruña, Ayuntamiento de A Coruña y Ministerio de Cultura, 2008, págs. 19-36. 
Rodríguez Ennes, Luis, "Cinco privilegios monásticos confirmados por Alfonso IX de León y Galicia en tierras de Laxe (A Coruña) el 25 y 26 de julio de 1228", GLOSSAE. European Journal of Legal History, 14 (2017), págs. 786-804.

Rodríguez Martínez, Luis, Historia del monasterio de San Benito el Real de Valladolid, Valladolid, Caja de Ahorros Popular y Ateneo, 1981.

Romero Tallafigo, Manuel, De libros, archivos y bibliotecas. Venturas y desventuras de la escritura, Gobierno de Canarias, Las Palmas de Gran Canaria, 2008.

Rueda Hernanz, Germán, España 1790-1900. Sociedad y condiciones económicas, Madrid, Istmo, 2006.

Ruiz Albi, Irene, La reina Doña Urraca (1109-1126): cancillería y colección diplomática, León, Centro de Estudios e Investigación "San Isidoro", 2003.

Valiña Sampedro, Elías, "El Cebrero en el camino de Santiago a través de Galicia", Compostellanum, 9, vol. 4 (1964), págs. 693-703.

Vázquez de Parga Iglesias, Luis; Lacarra de Miguel, José Ma y Uría Ríu, Juan, Las peregrinaciones a Santiago de Compostela, Madrid, Consejo Superior de Investigaciones Científicas, 1948-1949.

Villares Paz, Ramón, Foros, frades e fidalgos. Estudios de historia social de Galicia, Vigo, Edicións Xerais de Galicia, 1982.

Villares Paz, Ramón, Desamortización e réxime de propiedade, Vigo, A Nosa Terra, 1994.

Xunta de Galicia, Galiciana. Arquivo dixital de Galicia [en línea], disponible en <http://arquivo.galiciana.gal/arpadweb/gl/inicio/presentacion.cmd> [Consulta: 30/09/2017].

Yepes, Antonio de, Crónica general de la orden de San Benito, Madrid, Atlas, 1960, 3 vols.

Zaragoza Pascual, Ernesto, Los generales de la Congregación de San Benito de Valladolid. Vol. V: (1701-1801), Burgos, Abadía de Santo Domingo de Silos, 1984.

Zaragoza Pascual, Ernesto, "Abadologio del monasterio de San Benito el Real de Valladolid (1390-1835)", Investigaciones históricas. Épocas moderna y contemporánea, 23 (2003), págs. 211-212.

Zaragoza Pascual, Ernesto, "Índice documental de los monasterios benedictinos de Monforte, Chantada, Cebrero y Moraime (ss. IX-XVIII)", Diversarum rerum, 8 (2013), págs. 231-250.

Zaragoza Pascual, Ernesto, "Fernando el Católico y la reforma de los benedictinos y benedictinas españoles (1474-1516)”, Anuario de Historia de la Iglesia, 26 (2017), págs. 157-184. 